\title{
MJN \\ NURSING STAFF PERCEPTION REGARDING CRISIS MANAGEMENT IN SELECTED PRIVATE AND GOVERNMENTAL HOSPITALS
}

\author{
Nadia Taha Mohamed, Somaya Ahmed Bayoumy* \\ Nursing Administration Department, Faculty of Nursing, Cairo University, Egypt \\ *Corresponding Author's Email: somaya.aljazzar@gmail.com
}

\begin{abstract}
Crisis has always threatened human societies. Organizational studies long time ago has been interested in crises and crisis management (Bundy, Pfarrer \& Coombs, 2016). Accidents and crisis could be an internal or external event that can affect hospital staff, patients, visitors and community (Al Battat \& Som, 2013). Organizations are judged by their response to a crisis itself; choosing a proactive planning, respectful "systems approach" differentiates a good response from an average or poor one (Steen \& Aven, 2011). This study was aimed to assess nursing staff perception regarding crisis management in selected private and Governmental hospitals. A descriptive comparative design was used to collect data from one private and two Governmental hospitals. A convenient sampling technique was utilized in this study. A study sample composed of 530 nurses working in different clinical areas in the hospitals previously mentioned; they were divided into 230 nurses from private hospital and 300 nurses from Governmental hospitals. They were working in different clinical areas in Governmental hospitals. Data were collected utilizing Crisis management questionnaire that was adapted from El Gedely, (2006). Study result indicated a highly significant difference between nursing staff perceptions regarding all crisis management preparedness stages in private and Governmental hospitals. Nursing staff working in private hospital had high perception compared to those working in governmental hospitals. Continuing educational programs regarding crisis management to the nursing staff and good clarification for policies and communication within the organization are recommended by the researchers.
\end{abstract}

\section{Keywords: Crisis Management, Nursing Staff, Private and Governmental Hospitals}

\section{INTRODUCTION}

Crisis management is a process which the organization can use to deal with a problem such as disruptive and unexpected event (Azadian, Shirali \& Saki, 2014). This process is like nursing management process which include: planning, controlling, leading, organizing, and motivation prior to, during, and after a crisis (Bundy, Pfarrer \& Coombs, 2016). Crisis management is a system that includes clear roles, responsibilities and actions in the following areas: crisis prevention, crisis assessment, crisis handling and crisis termination. Crisis management is used to prepare nursing staff so that they can respond rapidly and adequately to crisis with proper communication techniques (Steen \& Aven, 2011). There are three components of crisis: a threat to the organization, the element of surprise, and a short decision time. Crisis Management provides a management framework for the prevention and reduction of harmful effects using available resource (Baubion, 2013).

Hospital preparation process is a dynamic and continuous process to identify changes in threats and risks. Hospitals preparation will be at the maximum level if their employees can do their task timely in a coordinated manner and accomplish appropriate performance in emergency situations or at any other 
crisis situation. During a crisis, hospitals and particularly nursing staff should have the ability to provide services in shortest time, and the human resources should organize and support the injured members (McHugh et al., 2011).

Hospitals that have preparation program and practice periodically suffered less damages when an unexpected event has occurred (Norman et al., 2012; Zarei, 2016). Lack of coordination and poor management is one of the most important barriers to provide comprehensive, continuous and accessible services with a good quality during critical situation (Fradgley, Paul \& Bryant 2015). The main goals of the hospital crisis management program in critical event is to increase the survivals, reducing complications like victims' physical and mental disabilities and relieving their injuries (Norman et al., 2012).

Bazregar et al., (2013); Bundy, Pfarrer \& Coombs (2016), indicated that there are three stages for crisis management program: pre-crisis prevention, crisis management, and post-crisis outcomes. Pre-crisis prevention stage focused on the organizational preparedness. Crisis management stages focused on the immediate actions taken by the manager. Moving from the pre-crisis prevention stage to crisis management; it was noted that organizational preparedness is a main factors to prevent a crisis, and also enhance the crisis management after starting event (Bundy \& Pfarrer, 2015). Finally, the post crisis stage emphasize on the learning outcome after the crisis.

James, Wooten \& Dushek, (2011), emphasized the role of crisis leaders who practice not only the skills but also the responsibilities of managing the organization in the pre- and post-crisis stages. Additionally, an important aspect is the characteristics of those leaders who encourage the team work during the crisis, as well as the high leadership skills of health care team. Crisis response strategies can involve purposeful communication and actions, including evidence that helps to avoid harm, in addition challenge to manage the organization's public image (Al Khalaileh, Bond \& Alasad 2012; Zavyalova et al., 2012; Bundy \& Pfarrer, 2015).

After crisis management stage, it is important to focus on post crisis outcomes (Wiersema \& Zhang 2013). It has focused initially on organizational learning. Learning is an evolving process that can emphasize on the event itself besides developing organizational capabilities after the crisis event (Zavyalova et al., 2012; Bajow \& Alkhalil 2014). Learning after crisis can help the organization to emphasize on the crisis circumstances and develop the needed strategies to deal with it (Madsen \& Desai, 2010). Learning from crisis can generate a new body of knowledge about a variety of crisis management techniques and especially about hospital safety (Haunschild, Polidoro \& Chandler, 2015), and increase motivation to inspect the causes and solutions of crisis (Bundy, Pfarrer \& coombs, 2016).

Hospitals' accreditation that is in regard of ensuring of healthcare quality, safe services presentation based on daily scientific evidence has various dimensions and requires standards in nine categories in management and leadership. The seventh case of these categories is in the management dimension and leadership in the case of crisis management and disaster (Haunschild, Polidoro \& Chandler, 2015; Graffin, Haleblian \& Kiley, 2016). Accordingly, for some years that measure of accreditation are ranked and rated in case of crisis management and disaster in all hospitals as measurement of periodic investigation and based on the hospitals obtained scores (Miniati \& Iasio, 2012). So that, the aim of present study is to assess nursing staff perception regarding crisis management in selected private and governmental hospitals.

\section{Significance of the Study}

Crisis situations are not new. As a result of increased globalization, population and technology, crisis can quickly become more serious in the scope beyond their origins. Health care organizations are trying to stay crisis management prepared for a long-term period. So, many researchers mentioned that crisis are huge, uncontrollable and can produce large-scale of disruption for all in the community and the normal healthcare system will be affected, leads to immediate threat to public health and interruption in healthcare services and the ability to respond to crisis. Crisis raised a human and infrastructure losses which is costly for any organization. So, the hospital preparedness and alertness should definitely increase. A successful crisis response can be enhanced through crisis management 
preparedness and applying new approaches to reduce its effects. Nurses have a main role in emergency situations at different managerial levels through planning and providing direct care during crisis. The role of nurses before, during and after crisis is very crucial as they must prepare, trained and have highly self-control on their responses. Now, Crisis management planning is particularly important. Hospitals have to be wisely able to manage these resources during crisis with consideration to the moral and ethical aspects of the nursing profession.

\section{METHODOLOGY}

Aim The study aimed to assess nursing staff perception regarding crisis management in private and governmental hospitals.

Design A descriptive comparative design was used in this study to assess nursing staff perception regarding crisis management in private and governmental hospitals.

Research Questions The following research questions were as guided the research study

1-What is nursing staff perception regarding crisis management?

2-What are the differences among nursing staff perception regarding crisis management in private and governmental hospitals?

\section{Study setting}

The present study was carried out in one hospital affiliated to governmental sector. Kasr El Aini hospital consists of 9 floors with bed capacity 5000 beds and 2189 nurses and two hospitals affiliated to private sector. The private hospitals involve all specialties and represents different services. The first private hospital consists of 8 floors with bed capacity 100 beds and 154 nurses. The second private hospital consists of 8 floors with bed capacity 110 beds and 120 nurses.

\section{Sample}

A convenient sampling technique was used in this study. It was composed of 530 nursing staff, with 230 nursing staff working in private hospitals, 12 head nurse and 218 staff nurse. About 300 nursing staff working in governmental hospital, 59 head nurse and 241 staff nurse. They were working in different clinical areas in private and governmental hospitals.

\section{Instruments}

Data collected using crisis management questionnaire developed by El Gedely (2006 ) and used to examine nursing staff perception regarding crisis management. It composed of two parts:-

$1^{\text {st }}$ part was personal data sheet that was developed by the researchers to collect data of the respondents such as position, qualification, gender, age and years of experience.

$2^{\text {nd }}$ part was crisis management questionnaire that included 42 self- reported questions to measure nurses' perception regarding hospital preparedness towards crisis which contain 5 main dimensions as follows: early detection stage of crises (13 items), preparedness stage (15 items ), dangerous manipulation stage (7 items ), recovery stage( 3 items) and learning stage (4 items). The scoring system was 5-point likert scale with 5 being strongly agreed and 1 being strongly disagree.

\section{Instrument Validity}

Instrument content validity was tested by a Panel of five experts from nursing administration department to assess the coverage, relevancy, and clarity of its items. Based on their recommendations, the necessary modifications were done.

\section{Instrument reliability}

Tool reliability was done using Cronbach alpha test. Total Cronbach alpha reliability coefficient was 0.93 . Early detection stage was $0.98,0.95$ for preparedness stage, and 0.94 for dangerous manipulation stage, 0.84 for recovery stage and 0.96 for learning stage of crises management.

\section{The pilot study}

About $10 \%$ participated in the pilot study sample which is 53 nurses (30 nurses from Kasr El Aini hospital; nine head nurse and 21 staff nurse; 11 nurses from first private hospital; three head nurse and eight staff nurse, and 12 nurses from second private Hospital; four head nurse and eight staff nurse to make sure that 
the instrument is clear and applicable and to estimate the time needed to fill the questionnaire. The time consumed ranged from 30 to 40 minutes. Nurses who participated in the pilot study were excluded from the study sample.

\section{Ethical consideration}

Hospitals directors and nursing director where asked for permission from nurse managers to facilitate data collection. The researchers ensured that, the autonomy and confidentiality were maintained during data collection.

\section{Procedure}

The aim of the study mentioned that the participant must fill the study instrument voluntarily. The instrument was distributed to nursing staff during different shifts while they were on duty, explaining the way of answering. The time consumed to fill the questionnaire ranged from 30 to 40 minutes. Data were collected during 2016 with duration of 8 months. Data were collected in morning and afternoon shift. The researchers handed the questionnaire to nurses and returned the questionnaire after acceptance to participate in the study.

\section{Statistical Design}

Descriptive statistics such as frequency, percentage distribution, mean score, standard deviation, independent T-test and one way ANOVA test were used in analyzing data presented in this study. Relative statistical tests of significance were used to identify the relationships among the study variables. Threshold of significances is fixed at $P$ value $\leq 0.05$.

\section{RESULTS}

Table 1 showed that, most of the study respondents $(95 \%)$ were staff nurses while the rest $(5 \%)$ were head nurses. About $60 \%$ of nurses had bachelor degree in nursing and $40 \%$ had technical degree. The majority of nurses $(83 \%)$ had less than 5 years of experience. while the rest had experience that ranged from 5 to less than 10 years of experience. About $68.7 \%$ of nurses' age ranged from 20 to 30 years old. While the age of the rest $(31.3 \%)$ ranged from 30 to 40 years old. About $70 \%$ of nurses were female and the rest (30\%) were male.
Table 1: Percentage Distribution of Nursing staff Personal Data in Private Hospitals ( $n=230)$

\begin{tabular}{|l|l|l|}
\hline Item (private) & No. & $\%$ \\
\hline Position & 218 & 95 \\
\hline Staff nurse & 12 & 5 \\
\hline Head nurse & 92 & 40 \\
\hline Qualification & 0 & 0 \\
\hline Nursing technical Diploma & 138 & 60 \\
\hline Associate technical nursing diploma & 0 \\
\hline Baccalaureate of nursing & 191 & 83 \\
\hline Years of experience: & 39 & 17 \\
\hline less than 5 years & 185 & 68.7 \\
\hline $5<10$ years & 72 & 31.3 \\
\hline Age & 77 & 30 \\
\hline $20<30$ year & 153 & 70 \\
\hline $30<40$ year &
\end{tabular}

Table 2: Percentage Distribution of Nursing Staff Personal Data in Governmental Hospitals ( $n=300)$

\begin{tabular}{|l|l|l|}
\hline Item (Government) & No. & $\%$ \\
\hline Position & 241 & 80.3 \\
\hline Staff nurse & 59 & 19.7 \\
\hline Head nurse & 229 & 76.3 \\
\hline Qualification & 57 & 19 \\
\hline Nursing technical diploma & 14 & 4.7 \\
\hline Associate technical nursing diploma & \multicolumn{2}{|l|}{} \\
\hline Baccalaureate of nursing & 31 & 10.3 \\
\hline Years of experience: & 105 & 35 \\
\hline less than 5 years & 71 & 23.7 \\
\hline $5<10$ years & 93 & 31 \\
\hline $10<20$ year & 11 & 3.7 \\
\hline 20 year and more & 112 & 37.3 \\
\hline Age & 98 & 32.7 \\
\hline $15<20$ year & 79 & 26.3 \\
\hline $20<30$ year & 45 & 15 \\
\hline $30<40$ year & 255 & 85 \\
\hline 40 year and more & \\
\hline Gender & \multicolumn{2}{|l}{} \\
\hline Male & Female & \\
\hline
\end{tabular}


Table 2 showed that, the majority of the study respondents $(80.3 \%)$ were staff nurses while the rest $(19.7 \%)$ were head nurses. About $76.3 \%$ of nurses had diploma school and $19 \%$ had technical degree and only $4.7 \%$ had bachelor degree in nursing. About $35 \%$ of nurses had experience ranged from 5 to less than 10 years of experience and $31 \%$ of nurses had experience ranged from 20 years of experience and more. About $37.3 \%$ of nurses' age ranged from 20 to 30 years old, $32.7 \%$ of nurses' age ranged from 30 to 40 years old and $26.3 \%$ of nurses were 40 years of age and more than $85 \%$ of nurses were female and the rest $(15 \%)$ were male.

Table 3: Nursing Staff Perception Regarding Crisis Management in Governmental Hospitals $(n=300)$

\begin{tabular}{|l|l|c|c|c|c|c|}
\hline & $\begin{array}{l}\text { Crisis } \\
\text { management } \\
\text { stages }\end{array}$ & Minimum & Maximum & Mean & SD & $\begin{array}{l}\text { Mean } \\
\%\end{array}$ \\
\hline 1. & Early Detection & 13 & 39 & 25.02 & 10.27 & 38 \\
\hline 2. & Preparedness & 15 & 45 & 29.28 & 12.23 & 39 \\
\hline 3. & $\begin{array}{l}\text { Dangers } \\
\text { manipulation }\end{array}$ & 7 & 21 & 14.21 & 5.76 & 40.6 \\
\hline 4. & Recovery & 4 & 12 & 7.86 & 3.34 & 39.3 \\
\hline 5. & Learning & 3 & 9 & 5.91 & 2.68 & 39.4 \\
\hline & Total & 42 & 126 & 82.28 & 32.75 & 38.3 \\
\hline
\end{tabular}

Table 3 showed that nursing staffs perceived their hospitals are prepared to crisis dangers manipulation stage (with mean $40.6 \%$ ) followed by learning and recovery stages (with mean $39.4 \%$ and $39.3 \%$ respectively) and lastly to preparedness and early detection stage (with mean 39\% and 38\% respectively).

Table 4: Nursing Staff Perception Regarding Crisis Management Stages in Private Hospital $(n=230)$

\begin{tabular}{|l|l|c|c|c|c|c|}
\hline & $\begin{array}{l}\text { Crisis } \\
\text { management } \\
\text { stages }\end{array}$ & Minimum & Maximum & Mean & SD & $\begin{array}{l}\text { Mean } \\
\%\end{array}$ \\
\hline 1. & Early Detection & 13 & 52 & 38.15 & 10.57 & 58.7 \\
\hline 2. & Preparedness & 15 & 60 & 46.96 & 12.94 & 62.6 \\
\hline 3. & $\begin{array}{l}\text { Dangers } \\
\text { manipulation }\end{array}$ & 9 & 28 & 23.05 & 6.40 & 65.9 \\
\hline 4. & Recovery & 6 & 16 & 13.20 & 2.87 & 66 \\
\hline 5. & Learning & 4 & 12 & 9.06 & 1.93 & 60.4 \\
\hline & Total & 47 & 168 & 130.42 & 31.84 & 60.7 \\
\hline
\end{tabular}

Table 4 showed that, Nurses perceive their hospital is prepared to crisis recovery stage (with mean \% 66) followed by dangers manipulation and preparedness stage (with mean \% 65.9 and 62.6 respectively) and lastly to learning and early detection stage (with mean
$\% 60.4$ and 58.7 respectively)

Table 5: Differences between Nursing Staff Perception regarding Crisis Management stages in Private and Government Hospitals

\begin{tabular}{|c|c|c|c|c|c|c|}
\hline \multirow{2}{*}{$\begin{array}{l}\text { Crisismanagement } \\
\text { stages }\end{array}$} & \multicolumn{2}{|c|}{ Govern. hospitals } & \multicolumn{2}{|c|}{ Private hospital } & \multirow[t]{2}{*}{$\mathbf{T}$} & \multirow[t]{2}{*}{$\boldsymbol{P}$} \\
\hline & Mean & SD & Mean & SD & & \\
\hline Early Detection & 30.7 & 12.27 & 38.15 & 10.57 & 14.35 & 0.00 \\
\hline Preparedness & 36.95 & 15.30 & 46.96 & 12.94 & 15.96 & 0.00 \\
\hline $\begin{array}{l}\text { Dangers } \\
\text { manipulation }\end{array}$ & 18.05 & 7.46 & 23.05 & 6.40 & 16.67 & 0.07 \\
\hline Recovery & 10.18 & 4.11 & 13.20 & 2.87 & 19.78 & 0.00 \\
\hline Learning & 9.76 & 3.75 & 9.06 & 1.93 & 16.85 & 0.00 \\
\hline Total & 105.65 & 40.98 & 130.42 & 31.84 & 17.19 & 0.00 \\
\hline
\end{tabular}

* Significant $<0.05 \quad * *$ highly significant $<0.001$

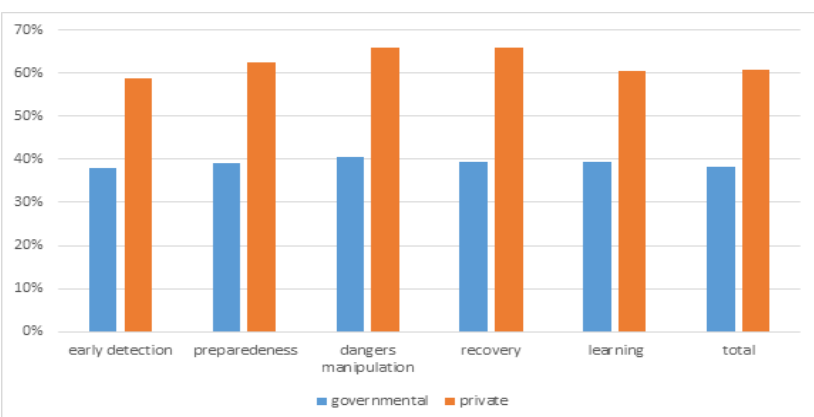

Figure 1: Differences between nursing Staff perception regarding crisis management stages in Governmental and private hospitals

Table 5 and figure 1 show that, there is a highly statistically significant difference between nurses' perceptions regarding all crisis management stages in private and Government hospitals except danger manipulation stage.

Table 6: Relationship between Nursing Staff Perception Regarding Crisis Management stages and Their Gender

\begin{tabular}{|l|l|c|c|c|c|c|c|}
\hline & \multirow{2}{*}{$\begin{array}{l}\text { Crisis } \\
\text { management }\end{array}$} & \multicolumn{2}{|c|}{ Male } & \multicolumn{2}{|c|}{ Female } & \multirow{2}{*}{$\boldsymbol{p}$} \\
\cline { 3 - 6 } & Mean & SD & Mean & SD & & \\
\hline 1. & Early Detection & 33.84 & 12.71 & 29.86 & 12.02 & 3.1 & 0.51 \\
\hline 2. & Preparednes & 39.21 & 13.33 & 36.34 & 15.75 & 1.96 & 0.00 \\
\hline 3. & $\begin{array}{l}\text { Dangers } \\
\text { manipulation }\end{array}$ & 20.07 & 6.78 & 17.49 & 7.55 & 3.51 & 0.00 \\
\hline 4. & Recovery Stage & 11.93 & 3.94 & 9.69 & 4.02 & 5.36 & 0.00 \\
\hline 5. & Learning stage & 11.99 & 3.89 & 9.15 & 3.47 & 7.07 & 0.00 \\
\hline & Total & 117.04 & 40.65 & 102.53 & 42.81 & 3.48 & 0.01 \\
\hline
\end{tabular}


Table 6 illustrated that, there were highly statistically significant relationships between all crisis management stages and nursing staff gender except early detection stage.

Table 7: Relationship between Nursing Staff Perception Regarding Crisis Management and Their Position

\begin{tabular}{|l|l|c|c|c|c|c|c|}
\hline & \multirow{2}{*}{$\begin{array}{l}\text { Crisis } \\
\text { management }\end{array}$} & \multicolumn{2}{|c|}{ Head Nurse } & \multicolumn{2}{|c|}{ Staff Nurse } & T & $p$ \\
\cline { 3 - 6 } & Mean & SD & Mean & SD & & \\
\hline 1. & Early Detection & 27.66 & 9.03 & 26.26 & 10.75 & 1.07 & 0.00 \\
\hline 2. & Preparednes & 32.93 & 11.59 & 30.50 & 12.55 & 1.47 & 0.01 \\
\hline 3. & $\begin{array}{l}\text { Dangers } \\
\text { manipulation }\end{array}$ & 15.15 & 5.32 & 14.87 & 5.88 & 0.37 & 0.00 \\
\hline 4. & Recovery Stage & 8.12 & 3.16 & 8.62 & 3.37 & 5.36 & 0.07 \\
\hline 5. & Learning stage & 8.83 & 3.39 & 8.61 & 3.55 & 1.06 & 0.11 \\
\hline & Total & 92.69 & 29.96 & 88.86 & 34.09 & 0.89 & 0.00 \\
\hline
\end{tabular}

Table 7 revealed that, there were statistically significance relationship between all Crisis management stages and nursing staff' position except in recovery and learning stage.

Table 8: Relationship between Nursing Staff Perception Regarding Crisis Management and Their Age, Experience and Levels of Education

\begin{tabular}{|c|c|c|c|c|}
\hline Item & Mean & SD & $\mathbf{F}$ & $P$ \\
\hline \multicolumn{5}{|l|}{ Age } \\
\hline $15<20$ years & 127.83 & 29.19 & \multirow{4}{*}{41.52} & \multirow{4}{*}{0.00} \\
\hline $20<30$ years & 100.12 & 48.57 & & \\
\hline $30<40$ years & 81.09 & 33.27 & & \\
\hline 40 year and more & 93.51 & 30.12 & & \\
\hline \multicolumn{5}{|l|}{ Experience } \\
\hline Less than 5 years & 122.30 & 32.41 & \multirow{4}{*}{31.96} & \multirow{4}{*}{0.00} \\
\hline $5<10$ years & 101.80 & 50.37 & & \\
\hline $10<20$ years & 76.20 & 30.71 & & \\
\hline 20 year and more & 94.47 & 31.62 & & \\
\hline \multicolumn{5}{|c|}{ Levels of Education } \\
\hline Nursing school & 82.97 & 33.35 & \multirow{3}{*}{87.45} & \multirow{3}{*}{0.00} \\
\hline Nursing institute & 129.82 & 39.89 & & \\
\hline Bachelor degree & 116.24 & 34.38 & & \\
\hline
\end{tabular}

${ }^{*}$ Significant $<0.05 * *$ highly significant $<0.001$
Table 8 illustrates that, there was highly statistically significant relationship between nursing staff perception regarding crisis management stages and their age, experience and levels of education.

\section{DISCUSSION}

The study aimed to assess nursing staff perception regarding crisis management in private and Government hospitals. Crisis management is a discipline within context of management consisting of skills and techniques that are required to identify, assess, understand, and cope with a serious situation, especially from the first moment it occurs to the point that recovery procedures begin (Groh \& Maximilian, 2014). Nursing staff should be aware of their present status and the status of the organization in crisis situations. This is important for expecting future alterations in the environment that may affect the ability of organization to operate (Bundy, Pfarrer \& Coombs 2016).

Regarding the nursing staff perception of crisis management in Government hospitals, the present study revealed that, the nursing staff of Government hospitals perceived their hospital were well prepared for manipulation of the crisis stage followed by learning and recovery stage and lastly to preparedness and early detection stage, this result might be due to that the nursing staff were concerned about the procedures to deal with the crisis when it already happen, how to control and minimize the effect of crisis, how to communicate quickly and properly with others to assure the magnitude of the crisis. Besides that, the hospital administration department must be prepared in the operating room with advanced technical instruments ready for use during crisis situations. Moreover results of the present study revealed that the nursing staff had a lack of information about the important stages of crisis that start with early detection stage to avoid crisis before occurrence with proactive planning, aiming to prevent the crisis before it occurs. But the health care organization does not prepared their staff well to the different stages of crisis and its importance

While in private hospital the result of the current study revealed that the nursing staff perceived the recovery stage highly significant followed by dangers manipulation stage then preparedness stage and lastly 
to learning and early detection stage. This might be due to the fact that the nursing staff perceived the most important stage is to recover after the crisis that happened without identifying the early signs of crisis to minimize its effects and how to deal during and after the crisis situations in their hospital. Accordingly, Groh \& Maximilian (2014), the aim of crisis management is to be well equipped, certify a rapid and adequate response to crisis, maintaining clear lines of communication and approving rules for crisis termination. The crisis management techniques include a number of consequences from the understanding of the impact of the crisis on the organization to preventing, alleviating, and overcoming of crisis (Bazregar et al., 2013). According to Bundy, Pfarrer \& Coombs (2016), they stated that to prevent the consequences of crisis is a great challenge to the organization. To reach the end of crisis quickly with limited negative effects, the leaders have to work persistently during this stage.

Regarding the differences between nursing staff perception to crisis management in Governmental and private hospitals, the current study revealed that, there was a highly statistically significant difference between nursing staff perceptions in relation to all crisis management stages in Governmental and private hospitals except danger manipulation stage. This result could be explained that the private hospital has effective and efficient resources, training courses for the nursing staff about crisis management beside that the work environment was completely different in private hospital than the Governmental hospitals. In the same manner Rojas, Seghieri \& Nuti, (2014) supports our results that nursing staff working in private hospitals are more preferable than working in public hospitals. Justifying that public sector organizations are controlled mainly by the political forces. For this reason the main constraints are imposed by the political system, while in private organizations, the owners have a direct monetary control to motivate managers to provide better performance. Similarly, improved performance of the staff also will affect the benefits of managers, because their payment is linked with the profit.

Regarding the relationship between nursing staff perception of crisis management and their gender, the present study revealed that there was a highly statistically significant relationship between all crisis management stages and nursing staff gender except early detection stage. This was reflected in total mean score that male nursing staff had the highest mean score compared to female nursing staff; this result could be due to that male nursing staff might attend educational courses about crisis management or gained their experiences from other organization or from the same organization which made their perception to the crisis management highly statistically significant. Related to our result Graffin, Haleblian \& Kiley (2016) said that there is a serious crisis in nursing and men are the solution. While Kahn, Barton \& Fellows (2013) mentioned that there were limited researches on preparation of health care workers for crisis.

Regarding the relationship between nursing staff perception of crisis management stages and their position, it is clear from the current study which revealed that there were statistically significance relationship between early detection stage, preparedness stage and dangerous manipulation stage but not in recovery stage and learning stage. This result might be due to that the head nurses had more experiences than the staff nurses. Many reasons can lead to this result such as; the head nurses as a nurse manager is highly educated than the staff nurses or due to more years of experiences of head nurses than the staff nurses or the head nurses enrolled in crisis management programs more than the staff nurses. Our result is supported by Fradgley, Paul \& Bryant (2015) who mentioned that familiarity with the health field make the manager capable of adapting to the nature of the crisis, or adequate experiences. The crisis manager must handle events like these in a timely and effective manner.

Regarding the relationship between nursing staff perception concerning crisis management and their age, experience and levels of education, the study revealed that there were highly statistically significant relationship between nursing staff perception of crisis management and their age, experience and levels of education. These finding could be due to that whenever the exposure to the critical situations improved the way of dealing with crisis, this will also increase their experience which improve their performance. Also their level of education had an effect on their perception regarding crisis management because the highly educated staff, older than the high school staff could be a clear factor affecting their perception regarding crisis 
situations. Accordingly, this result was supported by Noguchi et al., (2016) who found that the level of nursing license could lead to the difference in the preparation and length of educational programs for LPNs is two years after graduation from junior high school while RNs have three or four years of studying after graduation from high school. So, the professional level of RNs is broader and deeper than LPNs. Also Lim, Lim \& Vasu (2013) concluded that there was a strong positive relationship between nursing license, age and years of experiences in nursing staff and their perception for disaster stages.

\section{CONCLUSION}

The present study conclude that there was a highly statistically significant difference between nursing staff perceptions regarding all crisis management stages in private and Government hospitals as nursing staff working in private hospital had high perception compared to those working in Governmental hospitals.

\section{RECOMMENDATIONS}

Based on the finding of the present study the researchers recommend the following:

1. Training courses within the organizations mostly will improve the staff performance and rely on the employee's abilities.

2. The hospital administration can identify the critical points and defects through organizational survey to improve the effectiveness of quality management programs.

3. Systematic planning of crisis management is recommended, coordination is necessary inside and outside the organization during crises, reinforcement with good organization with the provision of necessary training and periodic exercises is required.

4. Updating the organizational culture, and structure can prevent system breakdowns that may lead to crises.

5. Clarity of policies and communication within the organization will help to minimize and overcome the consequences of crisis.

6. The manager of health care organization must constantly update on international and national processes that may affect the manipulation of crisis situations.

7. Continuous educational programs related to crisis management for the nursing staff could minimize the losses due to crisis.

\section{REFERENCES}

Abd-Elazeem, H., Adam, S. \& Mohamed G. (2011). Awareness of hospital internal disaster management plan among health team members in a university hospital. Life Science Journal, 8(2), pp 42-52.

Al Battat, A.R. \& Som, A.P.M. (2013). Emergency Preparedness for Disasters and Crisis in the Hotel Industry. SAGE Journal, pp 1-10.

Al Khalaileh, M.A., Bond, E. \& Alasad, J. (2012). Jordanian nurses' perceptions of their preparedness for disaster management. International Emergency Nursing, 20(1), pp 14-23.

Azadian, S., Shirali, G.A. \& Saki, A. (2014). Designing a Questionnaire to Assess Crisis Management Based on a Resilience Engineering Approach. Jundishapur Journal of Health Sciences, 6(1), pp 245-256.

Bajow, N. \& Alkhalil, S. (2014). Evaluation and analysis of Hospital Disaster Preparedness in Jeddah. Health, 6(19), pp 2668-2687.

Baubion, C. (2013). Strategic Crisis Management. OECD. Retrieved From: https://www.mmc.com/content/ dam/ mmc-web/Files/Strategic-Crisis-Management-paper-July-2013.pdf

Bazregar, R., Kankeh, H., Ahmadi, S., Hosseini, M., Rahgozar, M. \& Moradian, M. (2013). The evaluation of application of coordination based disaster response model in Rajaye hospital disaster preparedness. Iranian Journal of Nursing Research, 8(32), pp 10-18. 
Bundy, J. \& Pfarrer, M. (2015). A burden of responsibility: The role of social approval at the onset of a crisis. Academy of Management Review, 40(3), pp 345-369.

Bundy, J., Pfarrer, M. \& Coombs, W. (2016). Crises and crisis management: Integration, interpretation, and research development. Journal of management, 43(6).

El-Gedely, R. (2006). The real use of crisis management techniques in big Governmental hospitals in Ghaza. Ghaza Islamic University, Palestine.

Fradgley, E., Paul, C. \& Bryant, J. (2015). A Systematic review of barriers to optimal outpatient specialist services for individual with prevalent chronic diseases: what are the unique and common barriers experienced patient in high income countries? International Journal for Equity in Health, 14, pp 52.

Gervas, J. \& Meneu, R. (2010). Public health crisis in a developed society. Successes and limitations in Spain. SESPAS report Gaceta Sanitaria, 24(supl 1), pp 33-6.

Graffin, S., Haleblian, J. \& Kiley, J. (2016). Ready, AIM, acquire: Impression offsetting and acquisitions. Academy of Management Journal, 59(1), pp 232-252.

Groh, P. \& Maximilian, R. (2014). Strategic Management in Times of Crisis. American Journal of Economics and Business Administration, 6(2), pp 49-57.

Haunschild, P., Polidoro, F. \& Chandler, D. (2015). Organizational oscillation between learning and forgetting: The dual role of serious errors. Organization Science, 26(6), pp 1682- 1701.

James, E., Wooten, L. \& Dushek, K. (2011). Crisis management: Informing a new leadership research agenda. The Academy of Management Annals, 5(1), pp 455-493.

Kahn, W., Barton, M. \& Fellows, S. (2013). Organizational crises and the disturbance of relational systems. Academy of Management Review, 38(3), pp 377-396.

Lamin, A. \& Zaheer, S. (2012). Wall Street vs. Main Street: Firm strategies for defending legitimacy and their impact on different stakeholders. Organization Science, 23(1), pp 47-66.

Lim, G., Lim, B. \& Vasu, A. (2013). Survey of factors affecting health care workers' perception towards institutional and individual disaster preparedness. Prehospital and Disaster Medicine, 28(4), pp 353-358.

Madsen, P. \& Desai, V. (2010). Failing to learn? The effects of failure and success on organizational learning in the global orbital launch vehicle industry. Academy of Management Journal, 53(3), pp 451-476.

McHugh, M., Dyke, K. V., McClelland, M. \& Moss, D. (2011). Improving patient flow and Reducing Emergency Department Crowding: A Guide for Hospital. Agency for Healthcare Research and Quality, 11(12).

Miniati, R. \& Iasio, C. (2012). Methodology for rapid seismic risk assessment of health structures: Case study of the hospital system in Florence, Italy. International Journal of Disaster Risk Reduction, 2(1), pp 16-24.

Noguchi, N., Inoue, S., Shimanoe, C., Shibayama, K. \& Shinchi, K. (2016). Factors Associated with Nursing Activities in Humanitarian Aid and Disaster Relief. PLoS ONE, 11(3).

Norman, D., Aikins, M., Binka, F. \& Nyarko, K. (2012). Hospital All- Risk Emergency Preparedness in Ghana. Ghana Medical Journal, 46(1), pp 34-42.

Pourhosseinl, S. (2015). Key Aspects of Providing Healthcare Services in Disaster Response Stage. Iranian Journal of Public Health, 44(1), pp 111-118.

Rojas, D., Seghieri, C. \& Nuti, S (2014). Organizational climate: Comparing private and public hospitals within professional roles. Suma de Negocios, 5(11), pp 10-14 
Steen, R. \& Aven, T. (2011). A risk perspective suitable for Resilience Engineering. Safety Science, 49(2), pp 292-297.

Wiersema, M. \& Zhang, Y. (2013). Executive turnover in the stock option backdating wave: The impact of social context. Strategic Management Journal, 34(5), pp 590-609.

Withers, M., Corley, K. \& Hillman, A. (2012). Stay or leave: Director Identities and voluntary exit from the board during organizational crisis. Organization Science, 23(3), pp 835-850.

Zarei, V. (2016). Emergency Preparedness of Hospitals in Tehran and it's relation with crisis management measures. International Journal of Medical Research and Health services, 5(9S), pp 471- 478.

Zavyalova, A., Pfarrer, M., Reger, R. \& Shapiro, D. (2012). Managing the message: The effects of firm actions and industry spillovers on media coverage following wrongdoing. Academy of Management Journal, 55(5), pp 1079-1101. 